American Research Journal of English and Literature

ISSN (Online): 2378-9026

Volume 4, Issue 1, 2018, 1-13 Pages

DOI:10.21694/2378-9026.18004

AMERICAN RESEARCH JOURNALS

An Academic Publishing House

\title{
"We" Narrations: Building a Community through the Use of the First Person Plural
}

\section{Dr. Galia Hirsch}

The Department of Translation and Interpreting Studies, Bar Ilan University, Israel

Galia.Hirsch@biu.ac.il

Abstract: The goal of this paper is to investigate the purposes and implications of the pragmatic choice of the plural first person for narrations, instead of the more common use of the singular. The results of this analysis indicate the use of the plural form contributes to the creativity and innovativeness of the voice of the three novels analyzed: Hayinu He'atid (Ne'eman, 2011), The Wives of Los Alamos (Nesbit, 2014) and Shotgun Lovesongs (Butler, 2014). I argue that this choice is significant for the formation and depiction of the communities in these literary works; and that the changes of footing (Goffman, 1981) - the switches at some points to the first person singular - present the individuals' complex relationship with the community described.

Keywords: Pragmatics, first person plural, literary studies, community, footing

\section{INTRODUCTION}

This contribution deals with three literary works, which utilize a similar technique to create the effect of a community vis-a-vis the individual. This is achieved through the choice of the plural first person for the narrator's voice, instead of the more common singular first person narrations. The three literary cases studied - Hayinu he'atid [we were the future] (Ne'eman, 2011), The wives of Los Alamos (Nesbit, 2014) and Shotgun lovesongs (Butler, 2014) - all deal with different forms of communities. The choice of the plural form in these novels is significant for the construction of the communities described; and the deviations from this use, hence changes of footing (Goffman, 1981), contribute to express the complexity of the relationship the characters maintain with them.

What this paper sets out to examine is how the use of the plural form and the switch at some points to the first person singular makes the voice of these novels so unique. By "unique" I do not necessarily mean uncommon; as unnatural as they may seem, "we" narrations do appear in contemporary fiction, and have some antecedents in earlier writings (Richardson, 2006:37). Richardson (2006) refers to the usage of "we" as unnatural, while I prefer to use the term "unique" relying on Sarig's (2001) notion of uniqueness as part of the search for the authentic voice of the narrator.

Based on New Critics approach in general and specifically on Booth's (1961) notion of "the implied author" -an imaginary author who does not have a real biography, but may be assigned intentions via the text itself, and whose voice does not necessarily coincide with the narrator's - she regards authors' authentic voices as poetic artifacts, and believes in the ability of readers to construct the author's presence from the text.

Sarig (2001) identifies six qualities of the author's presence: sincerity - revealing the author's authentic position; self-revelation - disclosing private aspects of the author's inner truth; creativity and innovativeness - when writers can create fresh new thoughts and express them; intensity - ideas expressed directly, explicitly and even bluntly sometimes; interactivity - turning to converse with the readers; and use of poetic devices - to enhance, clarify and add an edge to the message.

www.arjonline.org

Page 1 
"We" Narrations: Building a Community through the Use of the First Person Plural

She exemplifies how the quality of creativity and innovativeness is achieved in Kastle-Bloom's story by means of experience re-framing (Sarig, 2001: 246). I claim that the framing of the events achieved by the use of the first person plural, and later the changes of footing occurring when there is a switch to the singular first person, contribute to the notion of creativity and innovativeness, which is designed in the literary works investigated here through the poetic use of personal pronouns (Sarig, 2001: 247-248).

\section{Description of THE Literary Plots}

Works written in the first person plural in their entirety are very rare (Fludernik, 1996:224); however, all three novels analyzed here use the plural to a large extent and open with it, as will be shown in the next sub-sections.

\section{Hayinu He'atid ([we were the future])}

The novelis based on the autobiographical experiences of Yael Ne'eman's on experiences as a child and later an adolescent in Kibbutz Yehiam during the 1960s-70s. Ne'eman presents small details that describe growing up in the huge social experience of the Kibbutz at that time, showing the individual emotional context as well as the political circumstances (Tal, 2011). Tal claims the interaction "between archival reports and sharp observations gives the book its special tone: a combination of irony and nostalgia, sometimes in the very same sentence". I argue that the book's special tone derives a lot from the use of the plural form.

\section{The Wives of Los Alamos}

Tarashea Nesbit's debut novel describes the domestic side of the story behind the making of the first atomic bomb in 1943. In a corner of New Mexico, a group of scientists were brought together to a military base and laboratory for the Manhattan Project. Though they were strangers, the scientists' wives joined together in adapting to a rugged military town where everything was a secret, including what their husbands were doing at the lab. The story is told through their collective voices(Steffens, 2014). This is achieved through various techniques that will be detailed subsequently.

\section{Shotgun Lovesongs}

Nicolas Butler's debut novel is a story of four close friends, Hank, Leland, Kip and Ronny, born and raised in a small country town of Wisconsin called Little Wing, whose friendship is slowly drifting in different directions as they reach their mid-thirties. Henry's wife, Beth, is another significant character, whose presence ignites the main conflict and whose perspective sheds light on the men's friendship.The novel is a shared memory only half-recreated of thefour characters. As with the other novels investigated here, though to a lesser extent, the shared memory is achieved through the use of the first person plural.

All the novels in question show similar techniques of revealing information, some of them might be derived from the plural form. As others, Scheibman (2004) suggests in "both spoken and written discourse it is quite common to find first person plural pronouns having singular or ambiguous number reference" (p. 381). Helmbrecht (2002) also agrees that no other pronoun can be as vague (p. 33). The three novels begin without precise information about the identities of the "we-communities", but they are all described at some point of plot, or at least some details about them:

(1) Et hasipurshelanusiparnule'atsmenukolhazman. Bikhfiyatiuyut. Be'alpe. Lif'amim

Our story we told ourselves all the time. Compulsively. By heart. Sometimes

hit'ayafnuodlifneishehithalnuubekhol zot siparnubemeshehsha'ot. Hikshavnurov 
"We" Narrations: Building a Community through the Use of the First Person Plural

we got tired before we started and yet we told for hours. We listened attentively

keshevehadlasheni, kibekholerevshebosuparhasipur, hithavrulanupratimhadashim,

to one another, because every evening the story was told, new details were revealed to us,

gam shanimrabotahreishekvar lo hayinu sham.

even many years after we were no longer there. (Hayinuhe'atid5)

(2) OVER THE BLACK Sea, The Mediterranean, the Pacific, the Arctic, the Atlantic; in sewers, in trenches, on the ocean, in the sky: there was a war going on. [...]IT WAS MARCH, gas was rationed; therefore the streets were quiet. We heard a car pull up in the driveway. (The wives of Los Alamos3)

(3) "WE INVITED HIM TO ALL of our weddings; he was famous" (Shotgun lovesongs 1).

\section{COMMUNITY VERSUS THE INDIVIDUAL}

As mentioned, my aim is to analyze and explain how the use of the first person plural contributes to the innovativeness and uniqueness of the novels in question; the following are some theoretical concepts relevant for the present study, with no attempt to cover the vast literature examining the use of personal pronouns from different angles.

Inclusive uses of the first person plural are those who refer to the speaker/writer and the addressees, exclusive uses are those who refer to the speaker and another person or group who are not the addressees. "Expression of inclusion and exclusion in discourse is not solely a referential operation; it has both social and interpersonal consequences" (Scheibman, 2004:377).

The exclusive "we" can be utilized to establish the difference between "us" and "them" and to pragmatically delimit or oppose groups, since in "semiotic and semantic terms, specific/generalized we and they are binary opposition to each other, positive v. negative, functioning as value laden antonyms" (Wales, 1996:61). "We" narrations resist the equation of narrator and protagonist, as they abandon the notion of individuality marked by the first person, in favor of a more communal narrator (Richardson, 2006:39).

In these cases,"we" is utilized to construct or change the social values of an ingroupness or outgroupness (Duszak, 2002:6).That is to say, a sense of community may be expressed by the use of the plural form. As Helmbrecht (2002) shows, instead of a referential relation, the first person plural can be used to express emotional or social connections and membership. "They are therefore per se a strong means to establish and reinforce social identities" (p. 42).

A discourse marked by I-isms would be marked as personal, regardless of the genre (Wales, 1996:71).In other words, according to the general scale of pronominal distancing from self, provided by Rees (1983 in Íñigo-Mora, 2004:33), "we" is more distant than "I". However, literature usually strives for a personal note; for that reason, it would be interesting to discover the reason the implied authors' chose to use the plural instead of the singular form, at least to some extent.

Ínigo-Mora (2004) shows the relationship between the first person plural and the concept of community and personal identity, and explains the difficulty in defining these concepts. Mason, for instance, presents the debate whether communities necessarily involve face to face relationships.In an attempt to answer some of the disputes, heoffers the term an "ordinary concept of community", in which the members shares values, a way of life, and there is also mutual recognition and identification with the group and its practices. A community in that sense differs from a mere society or association, where people promote their own interests, because at the 
"We" Narrations: Building a Community through the Use of the First Person Plural

very least, its members have common interests (Mason, 2000: 20). Nonetheless, a community in an even deeper sense, one that Mason (2000) coined a "moralized concept of community", must meet two further conditions: there must be solidarity (which to him is mutual concern) and no systematic exploitation.A particular group might also exhibit only some of the aspects or degrees of the two kinds of communities (Mason, 2000: 27).

However, as Íñigo-Mora (2004) points out, notions such as solidarity and exploitation are very hard to define. In her view, communities are based on relationships, but encompass most of all the idea of willingness - how the members of the community feel (p. 29).

By identifying with some, we also grow apart from others, since in general, the mental process of categorization foregrounds differences (Duszak, 2002:2). That might provide an explanation for Íñigo-Mora's (2004) claim that communities are often defined by contrast, by what their members are not (Íñigo-Mora, 2004:30).Both pronouns "we" and "they" are used in discourse to construct and manage social identities (Duszak, 2002: 6).

Ínigo-Mora (2004) suggests that the uses of "we" could be grouped into two main categories: a) power and distance; and b) identity, community and persuasion. It could be argued that the uses of both distance and identity are relevant to our case.

\section{CHANGES IN FoOTING}

The use of the first person plural in the literary works examined, and the following switch to a singular form, can be regarded as a change of footing. This analysis relies on Goffman's (1981) notion of footing, which has to do with the participant's alignment, set, stance, posture or projected self. A change in footing means a switch in the frame of events, it "implies a change in the alignment we take up to ourselves and the others present as expressed in the way we manage the production or reception of an utterance" (Goffman, 1981:128).

In terms of pronouns, their selective use may show more or less involvement in the encounter (Bull \& Fetzer, 2006:9). The changes of footing in the novels analyzed here may reflect the narrator involvement in the events depicted, and his/her attitude towards the community described.

\section{ANALYSIS OF THE LITERARY WORKS}

\section{Community and Diversity}

\section{Community}

The three literary cases studied here deal with communities, but the structure and circumstances of these groups are very different. To a certain degree, they can all be defined by an "ordinary concept of community" (Mason, 2000), since all groups share or at least used to share a way of life. Mason (2000) defines "way of life" as "a set of rule-governed practices, which are at least loosely woven together," (p. 22), and also as requiring some sort of cooperation. In Hayinu_He'atid the kids in the Children's group share everything: dwellings, meals, activities and beliefs. In The Wives of Los Alamos, the women share similar housing, problems and fates.

All the three groups analyzed can also be defined by a "moralized concept of community", because there is definitely a sense of solidarity and no systematic exploitation (Mason, 2000). The Children's group in the kibbutz is the tightest community of all three novels, not only in terms of sharing the same daily activities and being present all the time in each other lives, but also in sharing the same values and morals.

(4) Kolkahkrovimhayinuehadlasheni, kolhayomvekolhalayla, vebekhol zot

So close we were to one another, all day and all night, and yet 
"We" Narrations: Building a Community through the Use of the First Person Plural

lo yad'anuklumehad al hasheni. Veloyad'anuklum al atsmenu.

we knew nothing about one another, and knew nothing about ourselves. (HayinuHe'atid5)

It could be argued that the plural used here makes sense, and not solely as a literary device. However, there is no volunteer choosing of the community (Íñigo-Mora, 2004), and maybe that is why the narrator claims they do not really know each other. Helmbrecht (2002) considers the knowledge of the other members belonging to the group an important factor in the establishment of social identities. In Hayinu_He'atid the failure to truly know the members of the community could be part of the identity crisis the narrator depicts at the end of the novel.

Another mark of the community, towards the middle of The wives of Los Alamos, is when it is already formed, new arrivals take more time to become part of it, and this could also be noted linguistically because they are mentioned with their own names and not with the "we" formula:

(5) WE TOLD THE new arrivals -Pauline with the pink half-moon manicure that called attention to her stubby hands, Doris with the upswept victory roll, Betty with the calm voice -what was what in this town. [...] We told the new girls, [...] We watched them notice the dryness and lick their lips. We thought of our own dry lips and hands when we first arrived, and we thought, Silly thing, you are only making it worse. (The wives of Los Alamos125)

The first personal pronoun may describe different sized groups, and their composition may often vary during the course of the fiction (Richardson, 2006:38). In the cases analyzed here, the tightness of the communities coincides with the use of "we" form. It is conceivable that the first person plural is utilized to a lesser extent in Shotgun Lovesongs. It seems to tally with the fact that the characters used to share similar fates and surroundings, but have already parted ways when the main event of the plot occurs.

The narrator in Shotgun lovesongs is not as vague as the narrators of the other two novels. Each chapter is marked by the initial of the narrator's first name (although it takes the reader time to realize this). The first chapter is told by Henry, and he uses the first plural form more than the other characters, which emphasizes his connection to the land: he is the one who never left and is more tied up to the farm and place. The relationship to the land and community is a defining characterization in Shotgun lovesongs: Henry, the most likeable character, never left; Lee, the rock star, has a tractor that he likes to ride even though he has no crops; and Kip bought the old Mill, which almost ruined him. In fact, the real community described is Little Wing Wisconsin and people who feel connect it.

Hayinu He'atid is the only novel that gives an explanation for the unique use of the first person plural through the book, and in the next sentence comes the description of the making of the community:

(6) Dibarnuberabim. Kakhnoladnu, kakhgadlnu

We talked in the plural form. That is how we were born, that is how we were raised,

mebeithaholimve'adolam. Ofakenumeshunimve'akumim.

straight from the hospital and ever after. Our horizons strange and twisted. (HayinuHe'atid6)

Regardless of the explanation, there are some instances that do not seem very conceivable in the plural form, such as the following:

(7) "Sanenulehistaper, vebe'ikarsavalnumeshkaravshelFishel.

We hated cutting our hair, and most of all suffered from Fishel's lies." (Hayinu_He'atid10)

(8) "We wiped our hands on our apron and placed the apron on the dishes." (The Wives of Los Alamos3)

American Research Journal of English and Literature

Page 5 
"We" Narrations: Building a Community through the Use of the First Person Plural

The second example, as many others in The Wives of Los Alamos, does not seem tomake much sense, because wiping one's hands is a singular action made at a specific point in time; it is less probable that it was performed by all women at the same time frame.

This raises the issue of reliability concerning the use of the plural form. This specific use produces an unreliable narration that is bounded by limitations of the group described(Richardson, 2006:40). According to Richardson, the solution could be to see the "we" narrator as a more of a postmodern type of a first person narrator than a realistic one bounded by the epistemological rules of realism. Hence, these narrations can be regarded as transcending the limitations of conventional pronominalization (Richardson, 2006:50-60).

Richardson (2006: 40) connects the issue of unreliability with shared thoughts depicted as belonging to a single mind. Nonetheless, the degree of unreliability can vary.In The Wives of Los Alamos, single events are described as occurring to all members of the group, up to the point wherethe narration becomes highly unrealistic. So are the next examples, it is highly unlikely that all women were the same age and all had unfriendly pharmacists at their home towns:

(9) "We thought we would be joyful saying good-bye to the unfriendly pharmacist," (The Wives of Los Alamos9)

(10) "Though we were only twenty-five" (The Wives of Los Alamos10)

\section{Contrast}

The use of the third personal pronoun is a means to express collective identity (Richardson, 2006: 56). As ÍñigoMora (2004) points out, communities are also often defined by contrast, by what their members are not (p. 30). The group of children in the kibbutz is defined through their opposition to the children from Oren group, to their biological family, and to the adults in general. However, more than anything, the real group of opposition, the ones considered the others" by the children of the kibbutz all through the story, are the city people:

(11) Lif'amim, ahreishe'azavnu, nisinulesaper et sipurenule'ironiyim. Lo hitslahnu

Sometimes, after we'd left, we tried to tell our stories to urbanites. We could not

leha'avir et hasipur, lo et ha'alilavelo et haton. Kolenutsaram, kmoziufhaliliyotshel

transmit them, neither plot nor tone. Our voices grated like the off-key recorders of our

yaldutenu, gavohmidai o namukhmidai. Hityashnubaemtsa. Hamilimnafluhalulot

childhood, too high or too low. We gave up in the middle. The words fell hollowly

benenulebeinha'ironyim, kmoha'eynayimshenaflumimasregotehenshelimotenu

between us and the city people, like the stitches knitted by our mothers

besihathakibbutz, shotkotletsadhagvarimhamedabrim.

during the kibbutz assembly, silent next to the talking men. (HayinuHe'atid6)

The Los Alamos community is also built through contrast between the wives and the authorities, or other citizens of Los Alamos, and even their husbands. This contrast is sometimes marked by hate:

(12) "MANY OF US hated the women scientists. And the women scientists hated us, or they had better things to worry about." (The Wives of Los Alamos33) 
"We" Narrations: Building a Community through the Use of the First Person Plural

In a similar manner, in Hayinu He'atid there is hate and ignorance of the urbanites, of poor people, of the Druze (11). In Shotgun Lovesongs, the opposition between "us" and "others" is even more marked. The first sentence starts with a community formed by contrast: the farmers and Lee, the most famous and successful son of Little Wing. Lee is described with words representing his worldliness like: record company, New York City, tours, expensive presents, women, (1); and the community is described with words depicting their connection to the family and soil: our wives (1), food (1), land, our town, Little Wing (2).

As opposed to the other groups, there is more linguistic contrast between the members of that community, it is only logical from the plot's perspective, because the implied author is trying to tell a story about friends who have gone in different directions. In Hayinu he'atid the story is about children who were raised to be the same or part of a very tight community, and in The wives of Los Alamos it is about women who at least in some point in their lives shared a similar fate. It explains why in the last novel the community is more splintered, with opposition between Lee and the rest of the community, and later Kip and Ronny

It is interesting to mark that if communities are based on how the members feel, this is not a very tight community, it seems like Henry and Beth are the only ones feeling part of it. Lee is made to feel different by the way some people treat him, and Ronny only wants to leave but no one would let him.

Nonetheless, as Duszak (2002) suggests, community boundaries are usually fuzzy, forming a continuum of ingroupness - outgroupness; hence, it is possible for one member to feel included or excluded at different points in time (3). It is also true that rejection can be compatible with recognition (to denounce someone as a traitor must mean that they were once one of us) (Mason, 2000:25). Therefore, these members still form a part of the community albeit the differences:

(13) "After a period of time he came out of the tunnel and we took care of him as best we could because he was ours and he had no other family; [...] Ronny was Little Wing's orphan." (Shotgun Lovesongs7)

\section{Diversity}

The unique use of the first person plural in the three novels poses a challenge for the implied author, because even though the members of the groups share a lot of features, there is also diversity to a certain extent. This illustrates Richardson's (2006) point that"the variations in the specific individuals designated by the pronoun only serve to confirm the shared interests and sensibilities of all" (p. 50). The similarities and differences are presented in The Wives of Los Alamosat the very beginning of the novel:

(14) We were European women born in Southampton and Hamburg, Western women born in California and Montana, East Coast women born in Connecticut and New York, Midwestern women born in Nebraska and Ohio, or Southern women from Mississippi or Texas.... We had degrees from Mount Holyoke, as our grandmothers did, or from a junior college, as our fathers insisted. We had doctorates from Yale; we had coursework from MIT and Cornell. (The Wives of Los Alamos5)

(15) "and not matter who we were we wanted nothing to do with stating all over again," (The wives of Los Alamos 5)

In order to express the diversity, the implied author of this novel applies various methods, one of them is the repeated use of the conjunction "or" between phrases. Another common method to express the differences between the characters' circumstances is the use of quantity phrases, such as: "some of us", "a few of us", "those of us", "One of us".

(16) “OR IT DID not happen like that at all.” (The wives of Los Alamos 4)

American Research Journal of English and Literature

Page 7 
"We" Narrations: Building a Community through the Use of the First Person Plural

(17) "We married men just like our fathers, or nothing like them, or only the best parts." (The wives of Los Alamos 12)

(18) WE ARRIVED NEWLYWEDS, or with a seven-year itch, or still great friends, or no longer in love but trying to keep it together for our children, or for ourselves. Some ofus always expected disaster and kept the shades drawn low, some of us were quietly skeptical, although no one could tell, and we were nicknamed Polly. (The Wives of Los Alamos18)

(19) "A FEW OF us of us had experienced secrecy already. Our husbands were professors at Columbia or the University of Chicago and just that past month the Physics Lab was renamed the Metallurgical Lab," (The wives of Los Alamos 6)

(20) "THOSE OF US with husbands who were going to have manger in their titles got to know, immediately, the general location of our future home". (The wives of Los Alamos 6)

(21) "NOT ALL OF us were born in America and not all of us knew the academic world." (The wives of Los Alamos 12)

(22) "One of us set a pot red geraniums in front of the door so our children, our husbands, and ourselves could recognize our home. One of us put a black bowl of pinecones on the porch." (27)

The same technique is also used in Shotgun Lovesongs:

(23) "While the rest of us were in college or the army or stuck on our family farms, he had holed up in a derelict chicken coop and played his battered guitar in the all-around silence of the deepest winter." (Shotgun Lovesongs2)

Interestingly, in Hayinu_He'atid, there are almost no techniques to express diversity, this fact could have a contextual explanation: the community described is much more homogenous, the childrenof the group were born to it and expected to stay that way; they did not come from different places like "The wives",or part ways like the characters from Little Wing. Another explanation would be that the implied author intends to stress the lack of diversity in that particular "cookie cutter community".

\section{Changes in Footing}

As mentioned, a different footing implies a change in the alignment of the way the production or reception of an utterance is managed (Goffman, 1981:128). In the novels analyzed, changes of footing can be observed with the switch to a singular form, or when the narrators take another perspective, one of a different moment in time when they no longer form part of that community.

These changes of footing occur in Hayinu_He'atid with certain comments of the educated adult narrator, who has more insights about the implications of a life in the Kibbutz and more knowledge about the future of this institution in general; or in The Wives of Los Alamos when they later discover some harsh realities about the war.

(24) "Lo yad'anu shebe-1960 noladnulekokhavsheoro met mizman."

We didn't know that in 1960 we were born to a star whose light had long died." (HayinuHe'atid9)

The different perspective is usually one of disillusionment. In Hayinu_He'atid, the adult narrator no longer believes in the idea of the kibbutz. In The Wives of Los Alamos, the women are disappointed to discover the truth about their new home:

(25) "We were not told that the school, the homes, and the hospital had not yet been built" (The Wives of Los Alamos7) 
"We" Narrations: Building a Community through the Use of the First Person Plural

The unique use of the plural form becomes even more salient with the rare changes of footing to the singular form, especially in Hayinu_he'atid and_The wives of Los Alamos. The switch to the first person singular reflects the narrators' involvement in the events depicted, and their attitude towards the community described.

Similar changes of footing from the plural to the singular form have been reported in the inter-group speech of Las Madres de la Plaza de Mayo, but for different reasons: they reverted to "I" when it was in their best interest while confronting government officials (Wagner, 2002). The switch to the singular shows a different alignment and the speaker's wish to portray themselves as individuals instead of members of a group.

For example, a very private moment of family happiness, the birth of the narrator's brother (29), is described in Hayinu He'atid as part of the history of the Kibbutz, surrounded by other tales of the beginning of the settlement. The mother herself addresses her joy in terms of a collective achievement. Unlike her, the narrator shows her subversive attitude towards the event by reverting to the singular form, as if to imply that an event like this should be celebrated and remembered as something more intimate:

(26) Be-12 beyuni, shavu'aahreisheHantsavehayeladimaluleYehiam,

On June 12, a week after Hantza and the children came to Yehiam,

noladhatinokharishonbeYehiamatsmo. ZehayaOfer, ahi habekhor,

the first baby was born on the actual Yehiam location. It was Ofer, my older brother,

veimasheliamrabehaghakibbutz, o beserethayovel,

and my mother said in the Kibbutz festivities, or in the golden jubilee video,

shezothaytasimhashesahafa et kulam. Kmobaagadot,

that this happiness swept away everyone. Like in fairy tales,

hatsrifshelaveshel aba keilutsupabekholtuv. Zot hayta

it was as if her and Dad's shack was covered by all the riches. It was

havayahakhihazakashehayta la al beyahad. Al eikhefsharlismoahbeyahad.

the strongest experience of togetherness she had. Of how people can be happy together. (Hayinu he'atid29)

Yet it is not often that such changes of footing occur in that novel: only very rarely the narrator switches to the singular form, and then usually returns very quickly to the plural. Some of the rare instances when a switch does happen is in a romantic context, such as falling in love with Rami and Boaz.

A similar change of footing occurs in Henry's first chapter in Shotgun Love songs: the first time he uses the singular form is when he talks about his beloved wife Beth:

(27) "We let him be a few days, like we always did, and then my wife, Beth, invited him over to our farm for dinner and a bonfire." (Shotgun lovesongs 11)

Henry then goes back and forth between the singular and plural, with the last change of footing to the "I" form occurring when he describes his jealousy of Lee over a girl, this linguistically anticipates the main conflict between them, which revolves around Beth:

(28) "I choked on the smoke when he told me, coughed into the night before beating a fist against my chest." (Shotgun lovesongs15) 
"We" Narrations: Building a Community through the Use of the First Person Plural

Changes in The wives of Los Alamos occur towards the end of the novel, where more traditional forms of story telling take place:

(29) “ONE WIFE, BEATRICE, left to visit her parents in Kansas because her husband told the General her father was dying." (The wives of Los Alamos173).

However, there is a never a serious switch to the singular form, even when from the plot's perspective the community is falling apart with the discharging of the bomb:

(30) "SOME OF US felt more distant from the group; there were those of us who felt far away from the cheering and there were those of us who were happy to be a part of it. Because we disagreed with one another," (The Wives of Los Alamos192)

In all three cases, the dissolution of the group is marked by seeing everything from a different perspective, the outsiders". In two of the novels, Hayinuhe'atid and The wives of Los Alamos, people from the outside tend to regard the "we-group" as promiscuous and imagine bizarre sexual habits:

(31) “We saw our own lives from an outsider's perspective, with embellishments meant to fascinate and horrify: wild parties, lots of babies, you know what that means!" (The wives of Los Alamos193)

Apart from the above described small lapses, HayinuHe'atid is told in the plural form. The real and permanent change in footing irrupts when the author focuses on her own collapse after she first had to leave the kibbutz life for the army; and when she describes her incapacity to grasp how it is possible to live any other way. The linguistic transformation is significant for the characterization of the protagonist and the description of the change she undergoes:

\section{(32) Zot hayitianishenisdaktivelahenshuhrartimehatsava}

It was me that cracked and that's why I got discharged from the army

al se'ifesrimveahat,

on account of permanent psychological disability,

imshteite'udotshihrur, ahatkhulaveahatafora.

with two discharge certificates, one blue and one grey. (HayinuHe'atid106)

Her military service provided the narrator a first opportunity to be alone; the distancing from the community is described both by the content and by the use of the linguistic form:

(33) "Sham hayitilevadbapa'amharishona."

There I was alone for the first time." (Hayinuhe'atid107)

When she decides to quit the army, it is the first time the narrator does not follow everybody's lead and strays from the set path. At that point, the linguistic form shows the actions described in words.

Mason (2000) refers to a possible case where members of a community form identifications based on misconceptions, and when these illusions are shattered, they no longer regard their true identity as consistent with the community (p. 24). The narrator's rebellion in Hayinu_He'atid appears related to a similar shattering of illusions that involves a new political understanding: 
"We" Narrations: Building a Community through the Use of the First Person Plural

(34) Rakazhevantishehagdudsheboshiratihatsishanahaya

Only then I realized that the battalion I had served in for half a year was located in the bashtahimhakvushim.

occupied territories. (HayinuHe'atid107)

Interestingly, after the description of the desertion, there is another change of footing to the plural form, to indicate that the narrator forms again a part of a community: the Kibbutz deserters.

In Shotgun Lovesongs, the use of "we"slowly fades away when the plot evolves. However, Henry's last chapter starts with the plural from and presents some sort of a closure. The plural in these sentences is inclusive for him and Lee only, a proof that their friendship and fight are the main conflict in this story:

(35) “WE THREW NO DUST as we rocketed toward Lee's schoolhouse over those dewy midnight gravel roads." (Shotgun Lovesongs294)

This linguistic use also anticipates that Henry will forgive Lee, something the reader is not aware of at this point from the content.

(36) And what the old farmers and seed salesmen and implement dealers and teachers and real-estate brokers and tourists all laugh at, wonder at, was us: two grown men, friends, covered in gore, saying things like, "I love you, buddy," or "Breathe deeply, buddy." (Shotgun lovesongs 304)

As was the case with Hayinu_He'atid, in The wives of Los Alamos, the last paragraph reverts to the sense of community.

(37) WE LEFT HAPPY, we left relieved, we left thinking we had been a part of something unique, we left with doubts about our husbands, or about ourselves, or our country, or all of these, or none of it. We left wanting most what we had once had in the middle of the howling night, our friends: Louise, Starla, Margaret, Ingrid. We left pregnant, we left tired, we left, in some ways, just as we arrived: dusty and in need of a shampoo. (The Wives of Los Alamos230)

It is interesting to note that from the plot's perspective, The Wives of Los Alamos is the most forced community of all, but linguistically it never falls apart, the same methods of establishing community and diversity are employed till the very end.

\section{Discussion AND ConClusion}

The analysis demonstrates that the narration in the first person plural adds uniqueness to the point of view of the three novels in question: Hayinu He'atid, The Wives of Los Alamos and Shotgun Lovesongs.

The use of the first person plural is unconventional, while it is generally uncommon to start an interaction without an introduction of the group, all three novels show similar techniques of revealing information, opening without specific details about the identity of the communities in question.

The three literary cases deal with an "ordinary concept of community", but the structure and circumstances are very different, and so is the involvement of the narrator.The level of involvement of the narratorscoincides with the use of the first person plural. In Shotgun Lovesongs it is used to a much lesser extent, since the plot deals with the breaking of this specific community. Hayinu_He'atid presents a description of the tightest community of all, up to a point where it could be argued that the use of the pluralis not solely as a literary device. 
"We" Narrations: Building a Community through the Use of the First Person Plural

The implied authors of these novels make use of the plural to indicate an inclusiveness with the community described and an exclusiveness of people forming other groups, which is sometimes marked by hate or ignorance. The children's groupin the kibbutz is defined more than anythingby the contrast to the city people. The Los Alamos community is built on the contrast between the wives and the authorities, the women scientists and sometimes even their own husbands. In Shotgun Lovesongs, there are more marked differences between the members of the group itself, and the community boundaries are fuzzier.

The diversity within the communities is presented through similar techniques in The Wives of Los Alamos and Shotgun Lovesongs. Hayinu_He'atid does not seem to rely on similar methods, the lack of differences is stressed there to create the impact of the big change in footing with the switch to the singular form in the end.

Changes of footing occural so when the narrators show a later, more mature, perspective of the community, which exhibits their point of view afterthe dissolution of the groups. More significantly, the rare switches to the first person singularreflectthe change in the narrators' involvement and attitude towards their community. In Shotgun Lovesongs and Hayinu_He'atid, some of the changes of footing happen in a romantic context, but in the latter, the most salient change occurs when the protagonist is forced to live outside of the community.

In this lies the creativity and uniqueness of the frequent use of the first person plural in all three literary works. They create the sense of a community, what it means to be a part of it and what is the effect of losing it; while also presenting the price the individual has to pay in order to be able to form a part of a tight community. This is achieved not only through the advancement of the plot, but also through the specific unconventional choice of the plural for the narrators' voice.

\section{REFERENCES}

\section{Primary sources}

1. Butler, Nickolas. Shotgun lovesongs. New York: Thomas Dunne/St. Martin's Press, 2014. Print.

2. Ne'eman, Yael. Hayinu He'atid ['we Were the Future']. Tel Aviv: Ahuzat Bayit, 2011. Print.

3. Nesbit, Tara Shea. The Wives of Los Alamos: anovel. New York: Bloomsbury, 2014. Print.

\section{Secondary sources}

4. Booth, Wayne C. The Rhetoric of Fiction. Chicago: U of Chicago Press, 1961. Print.

5. Bull, Peter, and Anita Fetzer. "Who Are We and Who Are You? The Strategic Use of Forms of Address in Political Interviews." Text \& Talk - An Interdisciplinary Journal of Language, Discourse Communication Studies26.1 (2006): 3-37. Web.

6. Duszak, Anna. "Introduction." Us and Others: Social Identities across Languages, Discourses and Cultures. Ed. Anna Duszak. Amsterdam: John Benjamins, 2002. 1-28. Print.

7. Fludernik, Monika. Towards a 'Natural' Narratology. London: Routledge, 1996. Print.

8. Goffman, Erving. Forms of Talk. Philadelphia: U of Pennsylvania Press, 1981. Print.

9. Helmbrecht, Johannes. "Grammar and Function of We." Us and others: Social Identities across Languages, Discourses and Cultures. Ed. Anna Duszak. Amsterdam: John Benjamins, 2002. 31-49. Print.

10. Íñigo-Mora, Isabel. "On the Use of the Personal Pronoun We in Communities." Journal of Language and Politics3.1 (2004): 27-52. Print. 
"We" Narrations: Building a Community through the Use of the First Person Plural

11. Mason, Andrew. Community, Solidarity, and Belonging: Levels of Community and Their Normative Significance. Cambridge: Cambridge UP, 2000. Print.

12. Richardson, Brian. Unnatural Voices: Extreme Narration in Modern and Contemporary Fiction. Columbus: Ohio State UP, 2006. Print.

13. Sarig, Gissi. "Literate Texts, Articulating Selves: Qualities of Author's Presence - Writing-out Loud: Creating Author's Presence in Literate Texts." L1-Educational Studies in Language and Literature1 (2001): 235-72. Print.

14. Scheibman, Joanne. "Inclusive and Exclusive Patterning of the English First Person Plural: Evidence from Conversation." Ed. Michel Achard. Language, Culture and Mind. Ed. SuzanneKemmer. Stanford, CA: CSLI Publications, 2004. 377-96. Print.

15. Steffens, Daneet. “Book Review: The Wives of Los Alamos by TaraShea Nesbit-The Boston Globe." BostonGlobe. com. N.p., 24 Feb. 2014. Web. 13 Apr. 2015.

16. Tal, Ran. "Hebrew Fiction / Her Memories Are Mine - Books." Haaretz.com. N.p., 3 Mar. 2011. Web. 13 Apr. 2015.

17. Wagner, Lisa. "Strategic Alignment in the Discourse of Las Madres De La Plaza De Mayo." Us and others: Social Identities across Languages, Discourses and Cultures. Ed. Anna Duszak. Amsterdam: John Benjamins, 2002. 357-74. Print.

18. Wales, Katie. Personal Pronouns in Present-day English. Cambridge: Cambridge UP, 1996. Print.

Citation: Dr. Galia Hirsch, "'We" Narrations: Building a Community through the Use of the First Person Plural" American Research Journal of English and Literature, vol 4, no. 1, 2018, pp. 1-13.

Copyright (C) 2018 Dr. Galia Hirsch, This is an open access article distributed under the Creative Commons Attribution License, which permits unrestricted use, distribution, and reproduction in any medium, provided the original work is properly cited. 